\title{
Imaginar, contar e descrever as populações coloniais portuguesas, 1776-1875: notas de uma pesquisa em curso
}

\author{
Paulo Teodoro Matos*
}

\begin{abstract}
Em finais do século XVIII a Coroa portuguesa implementou um sistema regular de colecta de dados demográficos nos seus domínios ultramarinos. A partir do modelo definido, cada governador deveria enviar anualmente o numeramento da sua jurisdição. 0 Arquivo Histórico Ultramarino, em Lisboa, conserva mais de um milhar de tabelas estatísticas provenientes desde o Brasil até Macau. Esta documentação abre importantes horizontes para a história demográfica, social e colonial, apesar de relativamente negligenciada por historiadores e demógrafos. A partir destas fontes o projecto estuda a demografia e os processos estatísticos na construção do império português entre 1776 e 1875. Adiante discutimos o contexto desta investigação, com ênfase nas características da informação, variáveis e suas potencialidades, bem como uma agenda de investigação.
\end{abstract}

Palavras-chave: Império português. Demografía colonial. Recenseamento. Escravidão.

\footnotetext{
* Centro de Humanidades, Faculdade de Ciências Sociais e Humanas (CHAM/FCSH), Universidade Nova de Lisboa; Universidade dos Açores, Portugal (plmatos@fcsh.unl.pt).
} 


\section{Introdução}

“População e império. A demografia e os usos da estatística no império ultramarino português, 1776-1875" é um projecto de investigação internacional em curso desde 2013. ${ }^{1}$ Os investigadores começaram recentemente a traçar a história demográfica dos diversos domínios ultramarinos portugueses a partir de dados agregados disponíveis nos numeramentos coloniais. Ao mesmo tempo esta documentação tem sido analisada num contexto mais vasto, tentando-se reconstruir a rede burocrática e o contexto cultural em que tais numeramentos foram produzidos.

O suporte empírico reunido pela equipa assenta exclusivamente nos mapas estatísticos da população ordenados pela Coroa. ${ }^{2} 0$ período cronológico inicia-se em 1776 , quando se reforça o processo de ocupação do Brasil e se decreta a obrigatoriedade de execução anual dos “mapas" para cada um dos domínios. 0 âmbito cronológico termina em 1875, data em que se iniciou uma nova fase do colonialismo português, pouco antes de Conferência de Berlim.

Existem várias monografias demográficas sobre países europeus e de algumas áreas dos seus antigos impérios coloniais. No entanto, ainda escasseiam as contribuições de conjunto. No caso português, a existência de um significativo corpus de estatísticas da população disponível para o império ultramarino, desde meados do século XVIII, tem sido, geralmente, menosprezada por historiadores e demógrafos. Faltam-nos, ainda, ordens de grandeza sobre os quantitativos populacionais do império, em especial quanto à sua distribuição, etnicidade e condição jurídica. Quantos habitantes computar-se-iam para o império português em 1776 ou em 1850? Quantos escravos seriam recenseados pelas autoridades e qual o seu peso demográfico em cada uma das possessões? Em 1800 existiria mais população de origem europeia a residir em Angola ou em Goa, sede do Estado português da Índia?

A presente investigação pretende oferecer à comunidade académica e ao público em geral o primeiro estudo demográfico do império português e, ao mesmo tempo, contribuir para compreender a forma como a estatística da população se converteu num instrumento para a consolidação da soberania portuguesa nos seus domínios em África, Ásia e Américas.

A equipa do estudo estabeleceu os seguintes objectivos: identificar e reconstruir os principais indicadores demográficos das populações coloniais; distinguir e explicar os regimes demográficos existentes; mapear a rede burocrática usada na produção e recolha de informação estatística, identificando a evolução das categorias da população; e compreender as classificações dos mapas no contexto das necessidades das administrações coloniais, designadamente aos níveis militar, fiscal e territorial.

\footnotetext{
${ }^{1}$ Disponivel em: 〈http://colonialpopulations.fcsh.unl.pt〉.

2 Estes “mapas" partem de uma estrutura predeterminada, registando várias similitudes com os "mapas estadísticos de la poblacíon” produzidos na América espanhola (SANCHEZ-ALBORNOZ, 1975). No contexto europeu estas tabelas estatísticas também registam semelhanças com o modelo sueco, estabelecido em 1749, e conhecidas como Tabellverket (SKOLD, 2004).
} 
De forma a concretizar os objectivos propostos, temo-nos debruçado sobre um conjunto de indicadores demográficos para cada um dos seguintes espaços: Brasil (1776-1822), Madeira e Açores (1776-1834), Cabo Verde, Guiné-Bissau, São Tomé e Príncipe, Angola, Moçambique, Índia portuguesa e Macau (1776-1875) e, finalmente, Timor (1800-1875).

A historiografia tem insistido na tese de que as colónias portuguesas se encontravam numa relativa letargia desde o período liberal subsequente à independência do Brasil até a "Partilha de África" (c. 1870), apesar das amplas reformas legislativas levadas a cabo. Mas terá sido realmente este o caso? Além da perspectiva demográfica, os resultados deste projecto têm permitido atestar, com base na informação recolhida, a existência de possíveis dinâmicas de crescimento, que se evidenciam, por exemplo, tanto no aumento da população como na ampliação das áreas efectivamente controladas e administradas pelas autoridades portuguesas.

\section{Fontes e informação demográfica}

No império português, os primeiros numeramentos foram realizados nos principais centros urbanos do litoral no final do século XVII, por meio do registo de baptismos, casamentos e funerais executados pelas autoridades eclesiásticas locais, bem como pela elaboração de listagens de homens em idade de recrutamento. Mais tarde, surgiram numeramentos, sob a forma de róis, com o claro propósito de reforçar o controle fiscal e da propriedade. Estes inquéritos estavam confinados a áreas geográficas limitadas, eram produzidos com periodicidade irregular e não estavam organizados segundo um padrão uniforme (MATOS; SOUSA, 2014).

A mudança de paradigma na elaboração dos censos viria a ocorrer durante o período de governação do Marquês de Pombal (1750-1777), quando se procurou melhorar e expandir a produção e recolha de informação quantitativa da população. A contagem da população assumia-se, assim, como parte integrante do processo de gestão do território, convertendo-se os "mapas estatísticos" em instrumentos burocráticos, políticos e fiscais de grande alcance (MATOS; SOUSA, 2014; SANTOS, 2009).

A partir da década de 1770, a Coroa portuguesa viria a tornar obrigatória a produção de estatísticas anuais sobre a população e os seus movimentos, iniciando, assim, a compilação de tabelas da população sobre o império a partir de parâmetros comuns. Disso são exemplo as ordens régias emitidas em $1773,{ }^{3} 1776^{4}$ e $1797^{5}$ (BOTELHO, 2008; MATOS, 2013). Estes censos populacionais são contemporâneos (e em alguns casos, precedentes)

\footnotetext{
${ }^{3}$ AHU, códice 583, fls. $163-165$.

${ }^{4}$ AHU, códice 583, fls. 171-172 (ordem aos governadores) e fls. (ordem aos bispos).

${ }^{5} \mathrm{AHU}$, códice 424, fl. $155 \mathrm{v}$.
} 
às iniciativas observadas em outros impérios coloniais, como o britânico (1761) e o espanhol (1776) (ALDEN, 1963; BOTELHO, 2008). ${ }^{6}$

FIGURA 1

Mapa da população da capitania de Mato Grosso e Cuiabá de 1791

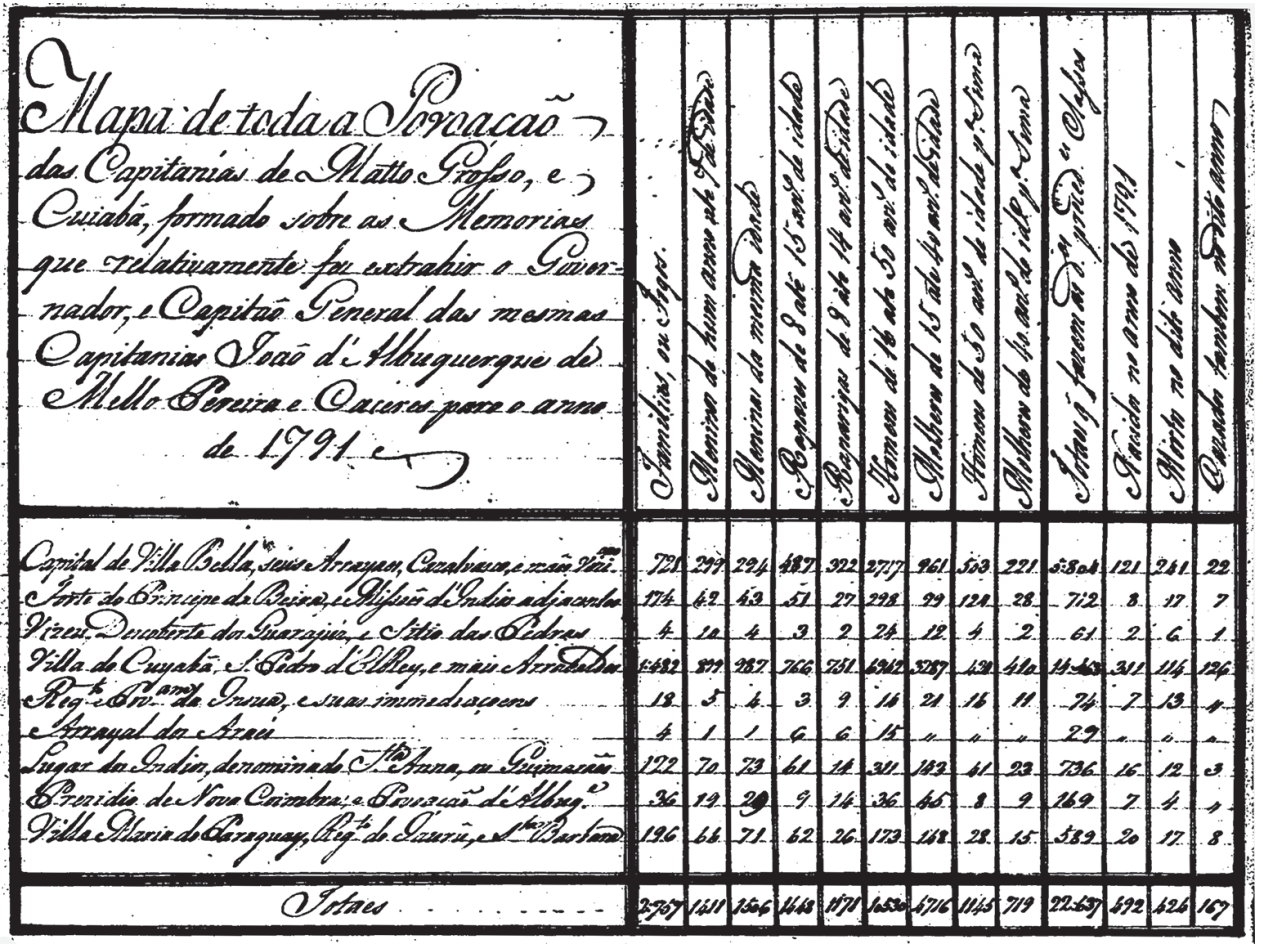

Fonte: Arquivo Histórico Ultramarino (AHU), Conselho Ultramarino, Brasil, Mato Grosso, cx. 29, doc. 1646 (5.08.1791).

De um modo geral, a maioria de numeramentos da população existentes até 1835 tem na sua origem as ordens régias de 1776 e 1797. Na maior parte dos territórios e circunscrições a informação deveria ser recolhida ao nível de cada freguesia, o que atesta a grande complexidade do processo e a dimensão destes mapas. No entanto, os registos demográficos não deixaram de registar particularidades próprias, especialmente quanto à classificação étnica dos habitantes.

A ordem real emitida pela Secretaria de Estado da Marinha e Negócios Ultramarinos, em 1776, determinava a divisão da população em oito grupos etários (quatro para cada sexo) e, ainda, o cômputo anual de nascimentos e óbitos. No entanto, o diploma é omisso quanto aos grupos sociais a incluir, realidade que sucedera no caso da América Espanhola (ALDEN, 1963). Dada a importância na caracterização das populações, essa lacuna foi corrigida pelo Aviso de 1797, expedido para diversas colónias do império (ALDEN, 1963; MATOS, 2013). No Brasil, contudo, boa parte dos governadores optou, desde a década de

\footnotetext{
${ }^{6}$ Uma discussão mais ampla acerca dos processos estatísticos no império pode ser encontrada em Matos (2013). Para o caso concreto do Brasil, ver Matos e Sousa (2015).
} 
1770, por incluir detalhes sobre etnia, estado civil e "índios domesticados", entre outras classificações. Nestes casos, os indivíduos eram frequentemente distinguidos entre "brancos”, “pardos” (mestiços), “escravos” e "índios domesticados” (ALDEN, 1963; LOVEMAN, 2014; RUSSELL-WOOD, 1997).

Em Angola os primeiros censos realizados em 1777 e 1778 apenas qualificavam os indivíduos como "livres” ou "escravos" (THORNTON, 1980, p. 421). Entre 1797 e 1835, as estatísticas anuais para cada presídio listavam o número de casas, sacerdotes e os habitantes brancos, mestiços e pretos. De igual modo, eram registados sexo, idade, estado civil, naturalidade e ocupação. Os mapas estatísticos fornecem, ainda, informação referente ao número de nascimentos, óbitos e "entradas" e "saídas" de população, o que os torna uma fonte de carácter excepcional (CURTO; GERVAIS, 2001; MATOS; VOS, 2013). ${ }^{7}$

No Estado português da Índia, com particular enfoque em Goa, Damão e Diu, a população era, até 1796, classificada exclusivamente com base na religião - “cristãos" e "gentios [= hindus] e mouros". A partir de 1797 os censos passaram a incluir os "cristãos brancos”, “cristãos naturais” (população nativa convertida), “pardos” (mestiços), "pretos" e "gentios e mouros". ${ }^{8}$ Em Macau, território sob a tutela de Goa até a década de 1840 , as autoridades produziam censos regularmente com informes sobre a população cristã e escrava, discriminando os indivíduos por idade e estado civil (VALE, 1996; RATO, 2015). É, ainda, de notar que os censos produzidos antes de 1822 já continham, de forma irregular, estimativas de população chinesa e/ou a "população embarcada", a qual era significativamente mais numerosa do que as de origens portuguesa e macaense (RATO, 2015). A partir de 1835, a contagem de residentes chineses, bem como de mouros, persas e cidadãos britânicos, holandeses e franceses, passou a ser efectuada de modo mais sistematizado.

À semelhança de outras colónias, também em Moçambique se procedeu a sucessivas alterações na categorização da população (NEWITT, 1995; SILVA, 2015; WAGNER, 2007). Embora a quantidade de "relatórios" e "censos" existentes nos arquivos históricos seja significativa, a área geográfica abrangida é assaz reduzida. Com a excepção de alguns centros urbanos (principalmente a Ilha de Moçambique, Inhambane e Tete), dispõe-se de pouca informação sobre os diferentes prazos da Coroa (WAGNER, 2007). Como nota Filipa da Silva (2017) para Moçambique, "being a Catholic was to a great extent a requirement to be regarded as a subject”. Por esta razão a maioria dos censos disponíveis incluía os não africanos (como, por exemplo, os baneanes e parses) e a população cristã, independentemente da cor.

\footnotetext{
${ }^{7}$ Estes mapas teriam na sua base as listas nominativas da população formuladas para tal propósito. A este respeito ver Guedes (2013). Com o generoso apoio da Fundação Calouste Gulbenkian, a equipa concluiu recentemente a construção de uma base de dados para este período, a qual permite a busca directa de dados ao nível de cada presídio (http:// colonialpopulations.fcsh.unl.pt/Angola/Populacao.php).

${ }^{8}$ Historical Archives of Goa, Monções do Reino, livro 157, fl. 311 (Decreto de 14.9.1796).
} 
No quadro da instauração relativa do liberalismo, importantes reformas na estatística demográfica foram levadas a cabo em 1835, embora no actual estádio de desenvolvimento do projecto ainda pouco se conheça sobre a sua aplicação nas colónias. Contudo, parece seguro que a generalidade destes censos foi realizada na sequência do Decreto de 20.10.1835, que determinava a execução de um censo anual pelos governadores dos distritos do Reino com informes sobre os grupos etários, relações laborais e profissões. É, por exemplo, neste contexto que já se identificou uma vasta série de censos para Goa $(1839,1842,1843,1846,1858)$, Damão $(1843,1846,1848)$ e Diu $(1842,1843,1848) .{ }^{9}$

Não é demais insistir que o acto de contar as populações não se assumia como um processo explícito. As categorias dos censos assumiam-se como construções sociais e políticas que resultavam da negociação com as autoridades locais (SILVA, 2011). Assim, o que poderia parecer um processo "imparcial” escondia, na verdade, intersecções entre várias disciplinas (como a sociologia e a antropologia) e esferas sociais (DORNEMANN; OVERATH; REINECKE, 2015). A título de exemplo, no caso da Índia portuguesa, seria apenas a partir da realização do extenso censo de 1851 que o registo da raça tornar-se-ia sistemático sem que, no entanto, a classificação religiosa desapareça. Esta realidade contrastava com os censos da Índia britânica, nos quais a raça sempre fora uma característica distintiva na classificação dos indivíduos (ANDERSON, 1991).

Uma questão em aberto reside no eventual hibridismo entre as normas oriundas do Reino e as adaptações introduzidas pelas próprias administrações locais. Até que ponto o Estado central deu autonomia aos governadores ultramarinos para executarem as adaptações necessárias? Esta é uma questão pertinente na medida em que os censos produzidos no quadro do liberalismo denotam assinaláveis diferenças entre as colónias.

\section{Discussão das fontes e resultados preliminares}

\section{Qualidade das fontes e território analisado}

Uma primeira questão colocada quanto ao tratamento desta informação respeita à sua qualidade. Para a maioria dos territórios não subsistem significativas interrogações a respeito da cobertura territorial dos censos, dada a reduzida superfície e a rede burocrática que permitiam reunir de forma mais ou menos eficiente os dados. Todavia, as grandes excepções eram, obviamente, Angola, Moçambique, Timor-Leste e, em menor grau, o Brasil, exactamente onde o peso demográfico era mais significativo.

O principal obstáculo dos dados populacionais de Angola, Moçambique e Timor reside na sua representatividade. Além de a ocupação humana estar restrita às zonas do litoral e próxima de certos rios, a representação estatística dos indivíduos confinava-se às zonas mais urbanas que se encontravam sob o controlo militar, os designados presídios. Sobre este assunto, o governador de Angola comentara em 1800:

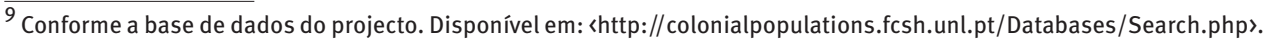


Quanto à exactidão [dos dados] dos presídios não me atrevo a aboná-la porque claramente vejo em alguns [presídios] como nos de Caconda ou Encoge erros palpáveis [...] porque eles [padres e militares] são homens que pecam por ignorância e com taes gentes, digame V. Exa., que quer que eu faça ${ }^{10}$

Mas atentemos à realidade brasileira, território que, por volta de 1800, englobaria cerca de $70 \%$ da população residente no ultramar. A cobertura destes vastos domínios, assim como a qualidade dos recenseamentos, poderia ser considerada, de certo modo, ambígua. Existiam adequado conhecimento geográfico e um controlo razoável das populações das capitanias do Rio de Janeiro, Minas Gerais, Pernambuco, Baía e Paraíba. Contudo, a zona do sul e várias regiões do interior (especialmente Amazónia) continuariam a ser colonizadas até meados do século XVIII (LIVI-BACCI, 2012; RUSSEL-WOOD, 1997). Em causa estava a rivalidade entre Portugal e Espanha quanto à fronteira, culminando com a assinatura do Tratado de Madrid (1750) e Santo Ildefonso (1778). É natural que em diversas capitanias, como na de São Paulo, a Coroa tivesse vigiado mais atentamente a execução dos mapas, tendo em vista a necessidade premente de ocupar as zonas em disputa com a Espanha. No entanto, é importante questionar a própria intervenção e zelo pessoal dos governadores no cumprimento desta matéria, cujo labor seria inculcado na própria cultura institucional das secretarias-gerais. São Paulo é exemplo paradigmático dessa situação (MARCíLIO, 1968), mas também podem ser enumerados os casos de Mato Grosso ou Goiás.

0 processo de recolha dos dados desde as relações primárias formuladas por párocos e capitães de ordenança até à execução dos mapas finais de toda a capitania constituía uma tarefa de natureza burocrática impressionante aos olhos de hoje, sobretudo tendo em conta o carácter regular da operação. Para a elaboração das tabelas eram convocadas várias entidades, passando a informação por um elevado número de mãos. Em última instância competia à secretaria-geral dos governos a responsabilidade pela confecção dos mapas. Contudo, sem a intervenção das redes territoriais da Igreja e do Exército, os governadores não conseguiriam dar cumprimento às ordens régias.

A análise da documentação, em particular dos ofícios que acompanhavam os mapas, sugere a existência de várias contrariedades na preparação dos quadros estatísticos finais, tais como a habitual relutância dos párocos na interpretação e execução dos formulários requeridos; a significativa extensão territorial das capitanias e o ténue conhecimento quer de toda a circunscrição, quer dos vários sectores populacionais; e o elevado número de agentes e entidades envolvido nos processos censitários, gerando, não raras vezes, mal-estar entre os responsáveis (ALDEN, 1963; MATOS; SOUSA, 2014).

As dificuldades de aplicação das normas e de execução dos próprios mapas refletiam-se, necessariamente, na qualidade da informação. A presença de populações flutuantes - como os escravos e, em certa grande medida, os indígenas - agravava as faltas de rigor no apuramento do total de efetivos. Por estas razões, os comentários apostos nos mapas

${ }^{10} \mathrm{AHU}$, Angola, cx. 95, doc. $42(14.04 .1800)$ 
pelos governadores, responsáveis máximos pelos trabalhos, afiguram-se fundamentais para uma aturada crítica da fonte.

De todo o modo, as incoerências apontadas não podem ser desanimadoras quanto à robustez da informação produzida. Quer o esforço de sistematização empreendido em cada uma das capitanias e governos, quer o controlo mais apertado por parte do Conselho Ultramarino sugerem que, progressivamente, as administrações foram capazes de desenvolver processos e rotinas mais fiáveis para a recolha da informação. Como bem notou Dauril Alden (1963), apesar de todas as falhas e incongruências de muitos dos mapas, estes constituem uma fonte insubstituível para a demografia e para a história social.

População total e escravatura no império português, 1776-1875

Tomando em linha de conta as considerações efectuadas na secção anterior, poderá dizer-se que a quantificação da população ultramarina entre 1776 e 1875 dependerá essencialmente do critério adoptado. Partimos de uma "perspetiva conservadora" relativamente aos territórios de Angola, Brasil, Macau, Moçambique e Timor-Leste, entendendo aqui os habitantes arrolados pelas autoridades e sob a sua administração direta. Estas estimativas incorporam, na medida do possível, os diversos grupos sociais, étnicos, religiosos, assim como os escravos.

TABELA 1

População residente nos territórios ultramarinos portugueses - 1776-1875 (secções temporais)

\begin{tabular}{|c|c|c|c|c|c|}
\hline Territórios & 1776 & 1800 & 1840 & 1875 & $1776-1875$ \\
\hline Angola & 150.000 & 174.742 & 378.923 & 433.397 & 1,1 \\
\hline Brasil & 1.426 .965 & 2.424 .641 & - & - & - \\
\hline Cabo Verde & 28.368 & 58.401 & 60.000 & 90.704 & 1,2 \\
\hline Damão & 16.379 & 28.221 & 34.070 & 33.837 & 0,7 \\
\hline Diu & 6.938 & 5.438 & 10.246 & 12.874 & 0,6 \\
\hline Timor & 52.327 & 112.345 & 232.774 & 294.157 & 1,8 \\
\hline Goa & 213.058 & 175.857 & 362.744 & 392.234 & 0,6 \\
\hline Guiné-Bissau & 4.640 & 4.735 & 4.912 & 6.154 & 0,3 \\
\hline Macau & 28.169 & 28.271 & 30.845 & 68.086 & 0,9 \\
\hline Moçambique & 49.407 & 32.983 & 68.411 & 93.000 & 0,6 \\
\hline São Tomé e Príncipe & 17.879 & 11.827 & 12.311 & 20.928 & 0,2 \\
\hline Totais & 1.994 .130 & 3.057 .461 & 1.195 .236 & 1.445 .371 & $-0,3$ \\
\hline Portugal & 2.566 .131 & 3.114 .793 & 3.737 .103 & 4.550 .699 & 0,6 \\
\hline Império (\%) & 77,7 & 98,2 & 32,0 & 31,8 & \\
\hline Império - TCA & \multicolumn{2}{|c|}{1,8} & $-4,6$ & 0,8 & \\
\hline
\end{tabular}

Fonte: Dados provisórios trabalhados pela equipa de investigação. As referências e parte das fontes compulsadas podem ser acessadas em 〈http://colonialpopulations.fcsh.unl.pt/Databases/Search.php〉. Os valores indicados em itálico correspondem a estimativas parcelares.

Ao longo destes 100 anos, a população ultramarina diretamente controlada pelas autoridades portuguesas ter-se-á se reduzido de 2 milhões para 1,5 milhão entre 1776 e 1875. A principal mutação nesta evolução deve-se à independência do Brasil, em 1822. Para esta data Tarcísio Botelho (2015, p. 101) computa para a "América Portuguesa" 
3.125.187 habitantes, aproximadamente $80 \%$ do total do império, ultrapassando assim a população portuguesa. Contudo, no arco temporal de 1776-1875, as colónias africanas, asiáticas e da Oceania registaram globalmente uma taxa de crescimento média anual muito acelerada $(0,9 \%)$.

Nesta reconfiguração política do império, a população residente nos domínios africanos subira, em termos relativos, de $12,6 \%$ (1776) para cerca de $35 \%$ (1875), devido ao maior controlo territorial em Angola e ao forte aumento demográfico nas ilhas de Cabo Verde. Na Ásia, o peso aumentara de $13,3 \%$ para $35,0 \%$, havendo que considerar a anexação das Novas Conquistas em Goa, mais que quadruplicando o território, e o registo mais sistemático da população chinesa em Macau (1840-1875). Na Oceania teria ocorrido o maior crescimento do império em termos relativos (de 2,6\% para 20,4\%, entre 1776 e 1875), apesar do recurso a estimativas "conservadoras” para população de Timor-Leste em 1875.

Após a independência do Brasil, uma das grandes questões parlamentares em discussão é se Portugal estaria em condições de rentabilizar as suas possessões, em particular as africanas. A busca de "Novos Brasis" debatia-se com o conhecimento limitado da geografia e o fraco controlo territorial, assegurado a partir de posições costeiras, fluviais, postos militares e influência em regiões do interior instáveis (OLIVEIRA, 2013; VALENTIM, 2004). A historiografia insiste no impacto muito limitado das medidas de fomento nas colónias até a "partilha de África" na década de 1870. Assim, apesar do voluntarismo político, o império “ainda estava no papel” (OLIVEIRA, 2013, p. 354).

O que estes dados informam é que, entre 1840 e 1870, o total de habitantes no império, diretamente registado pelas autoridades, havia crescido na ordem dos $21 \%$. Nas colónias africanas esse aumento fora muito expressivo tanto em Angola (14,3\%) e Moçambique (35,8\%), como nos pequenos arquipélagos de Cabo Verde $(51,7 \%)$ e São Tomé e Príncipe $(69,9 \%)$. Apesar de se poder convir na ideia de que não ocorreram mudanças estruturais no império desde a instauração do liberalismo (1820) até cerca de 1870, verdade é que, do ponto de vista demográfico e antes dos proveitos da economia de exportação do algodão, borracha, café e cacau, as autoridades foram progressivamente afirmando a sua presença territorial no ultramar.

A informação até agora recolhida permite quantificar, com alguma segurança, a população escrava residente no império para as diferentes colónias entre 1800 e 1840 . Os valores apresentados na Tabela 2 correspondem, grosso modo, à população efetivamente controlada pelas autoridades. De fora ficam os escravos que, embora sob o domínio teórico português, seriam pertença dos povos vassalos, especialmente em Angola, Timor e Moçambique.

Em 1800, cerca de $27,4 \%$ da população administrada pelo império seria escrava, 93,5\% da qual residindo no Brasil (BOTELHO, 2008; KLEIN; LUNA, 2010). Nesta possessão a distribuição era muito desigual, variando entre 15,6\% no Ceará e 53,9\% no Rio de Janeiro (BOTELHO, 2008; RUSSELL-WOOD, 1997). Em África, a população não livre sobrepunha-se à livre em São Tomé e Príncipe (55\%), onde ainda imperava uma tímida “economia de 
plantação". Bem diferente era a realidade cabo-verdiana (8,7\%), onde há muito que uma elite local (os chamados "brancos da terra") havia emergido. A maior parte do quantitativo escravo residia, porém, em Angola (16,7\%) e Moçambique (22,0\%). Na Ásia o peso da população escrava era residual, atestando o seu caráter essencialmente doméstico, mesmo em Goa, capital do outrora poderoso Estado português da Índia. No conjunto das possessões asiáticas pontuava Macau (4,1\%), mas, se excluída a população chinesa, os escravos elevavam-se a uns impressionantes 33,5\%.

TABELA 2

População escrava residente nas possessões ultramarinas portuguesas - 1800-1840 (secções temporais)

\begin{tabular}{|c|c|c|c|}
\hline \multirow{2}{*}{ Territórios } & \multirow{2}{*}{$\begin{array}{c}1800 \\
\%\end{array}$} & \multicolumn{2}{|c|}{1840} \\
\hline & & $\%$ & Razão de sexos \\
\hline Angola & 16,7 & 16,3 & 101,0 \\
\hline Brasil & 31,1 & - & - \\
\hline Cabo Verde & 8,7 & 9,4 & 96,5 \\
\hline Damão & 1,1 & 0,4 & 39,6 \\
\hline Diu & 0,6 & 0,8 & 59,3 \\
\hline Goa & 1,4 & 0,1 & 84,6 \\
\hline Guiné-Bissau & 11,9 & 35,1 & 109,0 \\
\hline Macau & 4,1 & 2,4 & 37,0 \\
\hline Moçambique & 22,0 & 32,3 & 140,7 \\
\hline São Tomé e Príncipe & 55,5 & 46,4 & 118,8 \\
\hline Império & 27,4 & 10,2 & 108,6 \\
\hline
\end{tabular}

Fonte: Os dados respeitantes à secção temporal de 1800 resultam das estimativas produzidas pela equipa usando as fontes primárias apresentadas no seu workshop internacional e que se encontram parcialmente publicadas nos Anais de História de Além-Mar, v. XVI, Lisboa, 2015. Os resultados para a secção de 1840 são originários dos dados de população escrava existentes para 1843 (Diário de Governo, 1849, Parte I, p. 751, n. 141).

Na década de 1840, o panorama alterara-se drasticamente. Mesmo admitindo alguma subavaliação dos dados em virtude da pressão inglesa, por volta de 1845 computavam-se 98.409 escravos nos domínios portugueses, correspondendo a $10,2 \%$ da população total segundo os dados populacionais de 1840. A vasta maioria concentrava-se em Angola $(62,7 \%)$, ainda que, em relação a 1800 , a proporção escrava se tenha mantido inalterada (cerca de 16,5\%). Em Moçambique o peso dos não livres correspondia agora a quase um terço dos habitantes, mas a sua representatividade no quadro do império não excedia os $22,5 \%$. São Tomé e Príncipe e Cabo Verde detinham o mesmo quantitativo de população escrava nesta secção temporal. No primeiro arquipélago, os não livres já não representavam a maioria, mas quase a igualavam (46,4\%), enquanto em Cabo Verde se reforçava a expressão da população escrava $(9,4 \%)$.

0 retrato da população não livre confirma um dado claro: em meados do século XIX a escravatura no império português confinava-se à África ( $98,5 \%$ do total), sendo aparentemente residual o seu peso absoluto e relativo nas possessões asiáticas. Esta proposição parece ser reforçada pelos dados relativos à razão de sexos. Nas colónias africanas, exceção feita a Cabo Verde, há predominância masculina, sobretudo em Moçambique, o que sugere o seu uso maioritário em contexto de economias de plantação. 


\section{Uma agenda de pesquisa}

Os mais de 1.700 mapas estatísticos da população até agora tratados revestem-se de significativo potencial para o estudo da história demográfica, social e colonial em 13 territórios espalhados por quatro continentes. 0 website e a sua base de dados fornecem já ao público, governos, associações não governamentais e instituições internacionais um importante repositório demográfico para uma população actualmente estimada em 260 milhões. Além disso, estes mapas constituem as primeiras estatísticas da população para territórios africanos e asiáticos, anteriores aos colonialismos britânico, francês e holandês e aos modernos recenseamentos coloniais da população que começam a surgir na década de 1870.

Além da reconstituição dos regimes demográficos vigentes, em especial das zonas de maior "pressão demográfica” com uma mortalidade excessiva, esperam-se, também, significativas aportações no campo das migrações livres e forçadas. No quadro da escravatura não faltam informações sobre o tráfico transatlântico nos séculos XVIII e XIX. ${ }^{11}$ Todavia, apesar da intensa produção historiográfica, ${ }^{12}$ ainda persistem interrogações sobre os efeitos e características demográficas da população escrava nos territórios de origem e destino. No Brasil, por exemplo, os padrões reprodutivos da população escrava estavam longe de ser homogéneos. 0 debate sobre os efeitos demográficos do tráfico negreiro em Angola neste arco temporal ainda persiste (MILLER, 1992; THORNTON, 1980; MANNING, 2013). O estudo sistemático da população angolana ao nível de cada distrito trará certamente novidades para alimentar este debate.

\section{Referências}

ALDEN, D. The population of Brazil in the late eighteenth century: a preliminary study. The Hispanic American Historical Review, v. XLIII, n. 2, p. 173-205, 1963.

ALEXANDRE, V. O império português (1825-1890): ideologia e economia. Análise Social, v. XXXVIII, n. 169, p. 959-979, 2004.

ANDERSON, B. Imagined communities. Reflections on the origin and spread of nationalism. Londres-Nova lorque: Verso, 1991.

BOTELHO, T. A população da América portuguesa em finais do período colonial (1776-1822): fontes e estimativas globais. Anais de História de Além-Mar, v. XVI, p. 79-106, 2015.

Políticas de população no período joanino. In: SCOTT, A.; FLECK, E. (Ed.). A corte no Brasil: população e sociedade no Brasil e em Portugal no início do século XIX. Porto Alegre: Oikos, 2008. p. 71-95.

CURTO, J.; GERVAIS, R. The population study of Luanda during the Late Atlantic Slave Trade, 1781-1844. African Economic History, v. 29, p. 1-59, 2001.

\footnotetext{
${ }^{11}$ Veja-se o conhecido repositório sobre o comércio atlântico de escravos, slave voyages, em: 〈http://slavevoyages.org〉.

${ }^{12}$ Mencione-se aqui, entre vários, os incontornáveis estudos mais recentes de Herbert Klein, Francisco Vidal Luna, Iraci del Nero da Costa e Manolo Florentino.
} 
DORnEmAnN, M.; OVERATH, P.; REINECKE, C. Travelling knowledge. Population statistics as "circulating entities". Contemporanea, ano XVIII, luglio-settembre, p. 469-472, 2015.

GUEDES, R.; PONTES, C. S. Notícias do presídio de Caconda (1797): moradores, escravatura, tutores e órfãos. In: PAIVA, E.; SANTOS, V. (Org.). África e Brasil no mundo moderno. 1. ed. São Paulo/Belo Horizonte: Annablume/UFMG, 2013. p. 153-180.

KLEIN, H. S.; LUNA, F. V. Slavery in Brazil. Nova lorque: Cambridge University Press, 2010.

LIVI-BACCI, M. Amazzonia. L'empero dell' acqua. Bologna: Società Editrice il Mulino, 2012.

LOVEMAN, M. National colours. Racial classification and the state in Latin America. Nova lorque: Oxford University Press, 2014.

MANNING, P. Migration in world history. Nova lorque: Routledge, 2013.

MARCílIO, M. L. La Villle de São Paulo. Peuplement et population. Roen: Publications de L'Université de Rouen, 1968.

MATOS, P. T. de; VOS, J. Demografia e relações de trabalho em Angola c.1800: um ensaio metodológico. Diálogos, v. 17, n. 13, p. 807-834, 2013.

MATOS, P. T. de; SOUSA, P. A estatística da população na América portuguesa, 1750-1820. Memorias. Revista Digital de Historia y Arqueologia desde el Caribe Colombiano, n. 25, p. 73-103, 2014.

MILLER, J. The numbers, origins and destinations of slaves in the eighteenth-century Angolan slave trade. In: INIKORY, J. E.; ENGERMAN, S. L. (Ed.). The Atlantic slave trade. Effects on economies, societies, and peoples in Africa, the Americas, and Europe. Durham: Duke University Press, 1962. p. 77-116.

NEWITT, M. A history of Mozambique. Indiana: Indiana University Press, 1995.

OLIVEIRA, P. A. Um império vacilante (c. 1820-c.1870). In: OLIVEIRA E COSTA, J. P. (Ed.). História da expansão portuguesa e do império português. Lisboa: Esfera dos Livros, 2013. p. 347-376.

RATO, D. The population of Macao, 1770s-1820s. Anais de História de Além-Mar, v. XVI, p. 181-204, 2015.

RUSSELL-WOOD, J. Late colonial Brazil, 1750-1808. In: BETHELL, L. (Ed.). Colonial Brazil. Cambridge: Cambridge University Press, 1997. p. 432-434.

SANCHEZ-ALBORNOZ, N. The population of Latin America. A history. Berkeley: University of California Press, 1975.

SANTOS, A. C. A. Aritmética política e a administração do Estado português na segunda metade do século XVIII. In: DORÉ, A.; SANTOS, A. C. A. (Dir.). Temas setecentistas. Governos e populações no império português. Curitiba: UFPR/SCHLA - Fundação Araucária, 2009. p. 143-152.

SILVA, C. N. Constitucionalismo e império: a cidadania no ultramar português. Coimbra: Almedina, 2011.

SILVA, F. R. Counting people and homes in urban Mozambique in the 1820s. Population structures and household size and composition. African Economic History, v. 45, n. 1, p. 46-76, 2017.

SKÖLD, P. The birth of population statistics in Sweden. The History of the Family, v. 9, p. 5-21, 2004.

THORNTON, J. The slave trade in eighteenth century Angola: effects on demographic structures. Canadian Journal of Economic Studies, v. 14, n. 3, p. 417- 427, 1980.

VALE, A. A população de Macau na segunda metade do século XVIII. Povos e Culturas. Portugal e o Oriente: passado e presente, Lisboa, n. 5, p. 241-254, 1996. 
WAGNER, A. Moçambique e o seu "diminuto número de habitantes": recenseamentos da população da África oriental portuguesa, no último quartel do século XVIII. Diálogos, v. 11, n.1/2, p. 239-266, 2007.

\section{Sobre 0 autor}

Paulo Teodoro de Matos é doutor em Demografia Histórica pela Universidade do Minho, Braga, Portugal. Investigador principal da Faculdade de Ciências Sociais e Humanas da Universidade Nova de Lisboa (FCSH-UNL) (Centro de Humanidades - Programa Investigador FCT 2013) e professor auxiliar convidado da Universidade Católica Portuguesa. Investigador responsável do projecto "Counting Colonial Populations. Demography and the use of statistics in the Portuguese empire, 1776-1875", financiado pela Fundação para a Ciência e Tecnologia, e coordenador executivo do Mestrado em História do Império Português na FCSH-UNL.

\section{Endereço para correspondência}

CHAM - Centro de Humanidades, Faculdade de Ciências Sociais da Universidade Nova de Lisboa Avenida de Berna, 26 C

1069-061 - Lisboa, Portugal

\section{Abastract}

Envisioning, counting and describing Portuguese colonial populations, 1776-1875: notes from research in progress

By the end of the $18^{\text {th }}$ century, the Portuguese Crown implemented a system for the gathering of demographic data in its overseas domains. In accordance with the model defined, each governor was to send a population count for the area under his jurisdiction annually. At the Arquivo Histórico Ultramarino, in Lisbon, there are over a thousand "population tables" from Brazil to Macao. This documentation significantly broadens horizons for demographic, social and colonial history, despite having been relatively neglected by historians and demographers. These sources allow for the study of demography and statistical processes during the construction of the Portuguese Empire between 1776 and 1875. The context of this research, with an emphasis on the particular characteristics of the sources, the data and their potential, as well as a research agenda shall be discussed further.

Keywords: Portuguese empire. Colonial demography. Census-taking. Slavery.

\section{Resumen}

Imaginar, contar y describir las poblaciones coloniales portuguesas, 1776-1875: notas de una investigación en curso

A finales del siglo XVIII la Corona portuguesa puso en marcha un sistema regulado de recolección de datos demográficos en sus territorios ultramarinos. A partir del modelo establecido, cada gobernador debía enviar anualmente la numeración de su jurisdicción. El Archivo Histórico Ultramarino, en Lisboa, conserva más de un millar de tablas estadísticas que provienen de lugares como Brasil o Macao. Esta documentación abre importantes horizontes para la historia 
demográfica, social y colonial, pese a la escasa atención que han mostrado historiadores y demógrafos por ella. Con base en estas fuentes, el proyecto estudia la demografía y los procesos estadísticos en la construcción del imperio portugués entre 1776 y 1875. Analiza además el contexto de esta investigación, con énfasis en las características de la información, las variables y su potencial, junto con un plan de investigación.

Palabras clave: Imperio portugués. Demografía colonial. Estadillos. Esclavitud.

Recebido para publicação em 01/02/2017 Aceito para publicação em 26/08/2017 